\title{
Formas e Definições de Mediação Cultural no Campo da Museologia e suas diferentes aplicações
}

\author{
Letícia Ferreira de Carvalho, \\ Larissa Caroline de Oliveira Miranda, \\ Eliane Cristina de Freitas Rocha'
}

\begin{abstract}
Resumo
O presente artigo busca melhor compreender de que maneira $\circ$ termo mediação cultural vem sendo trabalhado dentro do campo da Museologia. Para isso, foi realizado um levantamento das diferentes formas de mediação cultural presentes na literatura da área a partir de artigos de revistas de classificação Al a B3 encontradas na plataforma Qualis da Capes, num recorte de 10 anos (2007-2017). Foram analisados 63 artigos sobre a temática, dos quais apenas quatro abordaram experiências de mediação cultural de uma perspectiva horizontal, as quais são apresentadas e discutidas.
\end{abstract}

\section{Palavras-chave}

Mediação cultural; Museologia; Mediação; Museu; Ação cultural

\begin{abstract}
The present article searches to better understand in which way the term cultural mediation has been working in the Museology field. For this it was necessary to make a survey of the different ways of the cultural mediation finding on the literature of the field starting from magazine articles classified AI to $B 3$ found on the Qualis platform of Capes, in a I0-year cut (2007-20 I7). We analyzed 63 articles on the subject, of which only four attend with cultural mediation experiences from a horizontal perspective, which are presented and discussed.
\end{abstract}

\section{Keywords}

Cultural mediation; Museology; Mediation ; Museum; Cultural action

\section{Introdução}

Como sabemos, a Museologia é uma área do conhecimento que compreende diversos campos e possibilidades. As diferentes formas de mediação vem sendo uma vertente de estudos importante e em constante crescimento não somente dentro das instituições, onde cada vez vem ganhando mais espaço, mas principalmente dentro do campo de estudos da área. Para melhor compreendermos o papel das diferentes formas de mediação praticadas nas instituições museais, buscamos, primeiramente, estabelecer alguns conceitos básicos a respeito da mediação cultural e suas dimensões dentro do campo. Para isso, fizemos um levantamento bibliográfico sobre os conceitos de mediação conforme eles se apresentam nos periódicos da área de Museologia.

Nesse levantamento, foram encontradas diversas definições para o termo e suas dimensões, desde as mais pontuais e clássicas - a partir da raiz do significado da palavra mediação - até definições mais complexas encontradas na literatura, que serviram para balizar a análise da produção científica no campo da museologia. Tais definições são discutidas ao decorrer deste texto, além de

I Professora da Escola de Ciência da Informação (UFMG)

Doutora em Ciência da Informação, Mestra em Comunicação Social 
destacar relatos de experiência de práticas de mediação cultural inovadoras.

\section{Mediação Cultural e Literatura}

Em seu artigo Mediação e recepção: algumas conexões teóricas e metodológicas nos estudos latino americanos de comunicação, Maria Immacolata Vassallo de Lopes sugere que "A mediação pode ser pensada como uma espécie de estrutura incrustada nas práticas sociais e na vida cotidiana das pessoas que, ao realizar-se através dessas práticas, traduz-se em múltiplas mediações" (LOPES, 20I4: 68). Partindo deste conceito, podemos pensar a mediatização - conceito que relaciona o papel da mídia como mediadora da produção cultural. $O$ museu visto por esta perspectiva é instituição produtora de cultura.

Jean Davallon (2007) define, em seu artigo A mediação: comunicação em processo, que a mediação implica na necessidade de uma ação que exerce uma transformação e não uma simples interação entre elementos já construídos.

Em seu livro $O$ que é ação cultural?, Teixeira Coelho (1989) trata as diferentes formas de mediação de maneira sistemática, onde ele defende que a ação cultural e a ação educativa são duas coisas distintas e devem ser tratadas separadamente.

A cultura, em suas manifestações radicais (como a arte), procura e viabiliza o êxtase, o sair para fora de si, sair do contexto em que está para ver outra coisa, acima, por cima, para ver por dentro. A educação, embora pudesse ser outra coisa, em sua situação extremada com sinal negativo tem funcionado como o exato oposto ao ex-stase, ao estar fora: ela é o stase, o estar, quer dizer, partir daqui para voltar aqui mesmo, permanecer, metaforicamente preparar-se para o que existe, integrar-se ao que existe. São dois projetos de natureza e objetivos bem diversos que as utopias tentaram combinar, quase sempre desastradamente (TEIXEIRA COELHO, 1989: 29).

Já em 2003, em seu artigo Base de dados do inerte cultural a cultura da vida, Teixeira Coelho trata ação cultural como algo suplementar:

a ação cultural assume o caráter de medida suplementar e eventual baseada em um conhecimento empírico e imediatista, quase sempre subjetivo, de determinada situação social. Isso, porque a própria cultura é vista como algo suplementar, no máximo complementar, a ser obtida, proporcionada e desfrutada quando, e se possível, num segundo ou terceiro momento da vida individual e da comunidade (TEIXEIRA COELHO, 2003: 217 ).

Na Ciência da Informação encontramos o termo associado a designação de práticas operações e processos:

O termo mediação na Ciência da Informação brasileira tem sido empregado historicamente para designar práticas, operações e processos que envolvem o fluxo, a transferência e a apropriação da informação, bem como a elaboração de conhecimento e a produção de sentidos pelos sujeitos, podendo estar apoiada no agente mediador especializado, o bibliotecário ou “profissional da informação", e nos dispositivos tecnológicos (MARTINS, 20I4: I72). 
Como podemos perceber, o conceito de mediações é bastante amplo, podendo gerar uma infinidade de abordagens e diferentes sentidos. Thais Regina Franciscon de Paula define em sua tese, $A$ mediação em museus: um estudo do projeto "Veja com as mãos", que "O senso comum atribui na maioria das vezes, o sentido de neutralidade, imparcialidade, resolução de conflitos figurando a imagem de ponte para entender sua significação" (DE PAULA, 2012 :48).

Maiores informações a respeito da temática mediação, e as formas com que a mesma aparece em nosso cotidiano são disseminadas, e é importante discutirmos para que se delimite até que ponto estamos tratando de cultura ou educação e arte, e não apenas misturando conceitos já estabelecidos. É recomendado que se separe a Mediação Cultural da Mediação Educativa (Educação em Museus).

A respeito da mediação cultural podemos citar; de acordo com De Paula $(20 \mid 2)$

[...]pode ser entendida como trabalho de aproximação entre sujeitos e os produtos e artefatos culturais, tais como obras de arte, livros, exposições, espetáculos e o acesso aos espaços culturais, tendo como figura-chave o mediador que promove essa transação entre o processo de produção, difusão e apropriação (DE PAULA, 2012:57).

onde a autora justifica com a seguinte citação de Teixeira Coelho "[...] processos de diferentes naturezas cuja meta é promover a aproximação entre indivíduos ou coletividade e obras de cultura e arte." (TEIXEIRA COELHO, 2004, apud in DE PAULA, 2012, p 57).

Teixeira Coelho ainda sugere que essa aproximação é feita com o objetivo de facilitar a compreensão da obra, seu conhecimento sensível e intelectual com o que se desenvolvem apreciadores ou espectadores, na busca de formação de públicos para a cultura - ou de iniciar esses indivíduos e coletividades na prática efetiva de uma determinada atividade cultural. (TEIXEIRA COELHO, 2004, p. 248).

Já Davallon (2007) define a mediação cultural a nível funcional: a ação mediadora consiste em construir uma interface entre ambos os universos estranhos um ao outro nas palavras do autor, onde o mesmo coloca de um lado o público e do outro o chamado objeto cultural, a fim de que se proporcione uma apropriação do objeto pelo público.

Segundo Canedo (2008), Teixeira Coelho ao sustentar, a respeito da difusão cultural, a reafirmação do "mito do público apreciador" como propaganda cultural. A preocupação está "apenas em cultivar novos espectadores e admiradores, quer dizer, novos públicos, novos consumidores.” (TEIXEIRA COELHO, 200I, p. 10 apud in CANEDO, 2008).

Em Conceitos Chave da Museologia (20l3), um guia de grande importância para a área, surpreende-se por tratar o conceito de mediação de forma mecânica talvez por se tratar de um dicionário. Em sua definição de mediação, o livro retrata a mediação enquanto 'ponte', dentre outros conceitos genéricos "a mediação se coloca 'entre dois', em um espaço que ela buscará reduzir, provocando uma aproximação ou, dito de outro modo, uma relação de apropriação" (DESVALLÉES; MAIRESSE, 2013:52).Ainda em Conceitos Chave podemos encontrar definições mais pontuais e um tanto quanto restritas acerca da mediação enquanto sinônimo para intercessão:"A mediação designa a ação de reconciliar ou colocar em acordo duas ou várias partes, isto é, no quadro museológico, o 
público do museu com aquilo que lhe é dado a ver" (DESVALLÉES; MAIRESSE, 2013: 52) ainda conclui-se que:

[...] a mediação [...] desempenha um papel fundamental no projeto de compreensão de si em cada visitante - compreensão que o museu facilita. Com efeito, pela mediação dá-se o encontro com as obras produzidas por outros humanos, o que permite que se atinja uma subjetividade tal que promova autoconhecimento e a compreensão da própria aventura humana que cada um vive.Tal abordagem faz do museu detentor de testemunhos e signos da humanidade, um dos lugares por excelência dessa mediação inevitável que, ao oferecer um contato com o mundo das obras da cultura, conduz cada um pelo caminho de uma maior compreensão de si e da realidade por inteiro (DESVALLÉES, MAIRESSE 2013:54).

$\mathrm{Na}$ literatura da área, outras formas de mediação podem ser encontradas, essas, não necessariamente precisam ser trabalhadas e abordadas apenas de maneira sistemática podendo resultar boas ações como as educativas, mas a perspectiva que queremos tratar neste artigo trata-se de uma proposta dialogal que propicia o protagonismo dos saberes das comunidades e do saber coletivo . Conseguimos comprovar através de artigos encontrados durante a pesquisa que alternativas aparecem e podem auxiliar na busca por uma construção dessas outras formas de mediação.

\section{Metodologia}

A metodologia utilizada na pesquisa se deu em três etapas, a primeira buscando por meio de uma revisão bibliográfica, as definições do termo 'mediação' utilizadas na Museologia e na Ciência da Informação a partir de publicações da área, a segunda etapa do projeto se deu a partir de uma revisão sistemática da literatura científica, definindo um recorte a ser utilizado e a busca por revistas da área de Museologia na plataforma Qualis da Capes dos extratos de AI a B3 tratando da temática Museologia e Museus. Encontramos as seguintes revistas para o estudo: Caderno de Sociomuseologia; Revista Museologia e Patrimônio; Revista Museologia e Interdisciplinaridade; Anais do Museu Histórico Nacional; Anais do Museu Paulista:história cultural e material; Boletim do Museu Paraense Emílio Goeldi Ciências Humanas; MIDAS: Museus e estudos interdisciplinares e a Revista Museu de Arqueologia e Etnologia. Após a recuperação das revistas citadas acima, foi feito uma seleção quantitativa de artigos que tratassem o tema mediação num período de 10 anos (2007-2017), a partir da busca na plataforma das revistas selecionadas, através da utilização dos termos "mediação, museu”," "mediação, museus” "mediações, museu" e "mediações, museus". Foram encontrados um total de 250 artigos em revistas voltadas para a temática "Museologia" e 210 artigos para a temática de "Museu", os quais ainda passaram por mais um recorte pois, a pesquisa pelos termos ocorre dentro dos volumes da revista, portanto, os termos pesquisados estão inseridos dentro dos textos, e não necessariamente têm relação com o tema a ser trabalhado.

$\mathrm{Na}$ terceira parte da pesquisa, iniciamos a leitura e análise dos resumos dos artigos recuperados e seleção daqueles que abordassem de fato as formas alternativas de mediação cultural ou que colaborassem a uma definição mais flexível do termo. Nessa fase, os artigos foram reduzidos a um total de 63 relacionados a museus e Museologia. Foi criado um banco de dados para lança- 
mento dos títulos, autores dos artigos, palavras-chave, resumo e categorização das formas de mediação presentes em cada um deles. Após leitura desses artigos e seleção dos que se alinhavam à pesquisa, os seguintes autores podem ser destacados: Luciana Pasqualucci, Mário Chagas, Waldisa Rússio, Tereza Scheiner, Ulpiano de Meneses,Ana Catarina Nunes, Manuelina Maria Duarte Cândido, Nei Clara de Lima, Isabel Lourenço Gomes, entre outros.

Ainda nessa etapa, selecionamos os artigos que abordavam relatos de experiência a partir da perspectiva dialogal para auxiliar na compreensão das dinâmicas da mediação cultural de maneira empírica, destacamos os seguintes artigos: Filho de peixe sabe nadar: histórias e estórias com objetos de Ana Catarina Nunes (2016); A Festa do Divino Espírito Santo: patrimônio cultural, políticas públicas e sua interface com a Museologia de Bárbara Mançanares e Luiz Carlos Borges (2017); Ocupe o museu (com) memórias de Goiânia: O público como construtor de conteúdos de Manuelina Maria Duarte Cândido e Nei Clara de Lima (20l4) e Epopeia Paulista:A experiência do ateliê-residência no Museu de Arte Contemporânea da Universidade de São Paulo de Alecsandra Matias de Oliveira (20I4).

No artigo Filho de peixe sabe nadar: história e estórias com objetos, a mediação cultural aparece a partir da perspectiva da experiência participativa do público escolar e a comunidade ao entorno do Museu Marítimo de ílhavo em relação à história da pesca do bacalhau através do contato direto. Onde, segundo a autora:

(...) através deste projeto, as memórias que ecoam nestas estórias foram salvaguardadas e permitiram a ativação do sentimento de pertença e identidade à história da pesca do bacalhau. Os objetos atuaram enquanto mediadores entre a comunidade, a escola e o museu. (NUNES, 2016: 7).

Ainda segundo a autora, através do conhecimento adquirido, os próprios alunos orientavam a exploração dos objetos, tornando-os assim agentes mediadores, a partir da aproximação e identificação gerada pelas próprias investigações.

No artigo A Festa do Divino Espírito Santo:patrimônio cultural, políticas públicas e sua interface com a Museologia, os autores apontam que a festa se dá como um momento de "retorno" onde a comunidade se reconecta com suas crenças e identidade. Ainda segundo os autores, ocorre também nesse momento a aproximação dos saberes da comunidade e trocas comerciais em prol de um bem comum. Nesse sentido, a mediação cultural ocorre de maneira simbólica através da realização da festa, onde a mesma segundo Maçanhares e Borges:

\footnotetext{
A Festa, enquanto ato performático e espaço de mediação, promove o religare não só entre homens e Divindade, mas, sobretudo, entre homens e homens, que se relacionam, estabelecem trocas afetivas e comerciais; que se identificam por compartilhar determinadas crenças e valores, por compartilharem o mesmo espaço identitário - São Bartolomeu. (MAÇANHARES, BORGES, 20|4: |48)
}

Esse trecho demonstra que a mediação cultural pode ser algo intangível sem a necessidade de um interlocutor.

O artigo Ocupe o museu (com) memórias de Goiânia: $O$ público como construtor de conteúdos mais uma vez vai justificar o fato de que a mediação cultural acontece a partir da perspectiva do público e para o público, é importante que ocorra uma interação entre todas as partes envolvidas. Mesmo quando a me- 
diação cultural acontece a partir de um indivíduo interlocutor, ela não necessariamente precisa se dar de maneira mecanizada. Nesse caso, especificamente, o público não é apenas receptor, mas também produtor de conteúdo através da curadoria compartilhada. Nesse sentido, segundo os autores, a instituição assume o papel de mediadora entre as experiências e narrativas individuais e sociais dos participantes:

\begin{abstract}
Ao invés de propor um discurso único e com pretensões de totalidade, o MA apropriou-se do caráter fragmentário da sua época e da memória dos indivíduos que vivem no seu entorno e colocou-se ao serviço das histórias que aquele grupo pretendia contar, histórias que enlaçavam a vida pessoal com a vida da cidade, a infância e as adolescências de cada um dos participantes com a história da construção da cidade e com os dias atuais. (CÂNDIDO, LIMA, 20।4:7)
\end{abstract}

Em Epopeia Paulista: A experiência do ateliê-residência no Museu de Arte Contemporânea da Universidade de São Paulo, a experiência de criação se dá de maneira co participativa entre colaboradores, voluntários, artistas profissionais e espontâneos, mas, principalmente pela artista autora da obra. Neste caso, a mediação cultural acontece como consequência das experiências do próprio público em relação a artista e a obra, onde os mesmos tornam-se construtores da memória a ser incorporada na obra.

As diferentes formas de mediação encontradas nos quatro relatos de experiência nos auxiliam a melhor compreender a importância da mediação cultural a partir de uma perspectiva horizontal. Há ruptura com a perspectiva vertical, considerada como aquela em que a instituição se torna detentora do conhecimento, e seu público é visto apenas como mero espectador, colocando a mediação então sob a competência de um terceiro, o educador, posto ali como interlocutor, como ponte. Nos quatro relatos aqui são destacadas formas alternativas à perspectiva da mediação como atividade de transmissão de mensagens como estratégica mercadológica para atrair público para o já instituído.

\title{
Considerações Finais
}

O conceito de mediação cultural é complexo, pois diz respeito às definições de cultura e ação cultural, constantemente em discussão e em processo de revisão por autores tais como Teixeira Coelho. Assim como ocorre no campo da Museologia como um todo, a mediação cultural tem seu campo teórico proveniente de um reflexo da práxis.

A partir do que foi pesquisado, podemos concluir que o campo da mediação cultural é fértil para pensar formas de atuação na Museologia que rompem com as definições clássicas restritas às ações educativas não dialogais e que não consideram o público como participante dos processos instituintes do museu.

\section{Referências}

CÂNDIDO, Manuelina Maria Duarte; LIMA, Nei Clara de. Ocupe o museu (com) memórias de Goiânia: $O$ público como construtor de conteúdos. Midas. Museus e estudos interdisciplinares, n. 3, 2014. Disponível em: < https://journals. openedition.org/midas/505> acesso abril de 2018. 
CANEDO, Daniele Pereira. Democratização da Cultura. In: ALMEIDA, Maria Cândida (Org.). Mais Definições em Trânsito. Salvador: Universidade Federal da Bahia, 2006. Disponível em: <http://www.cult.ufba.br/maisdefinicoes/DEMOCRATIZACAODACULTURA.pdf> .Acesso em: maio de 2018.

COELHO, Teixeira. Banco de dados: do inerte cultural à cultura da vida. In: Políticas Culturais para o Desenvolvimento. São Paulo. UNESCO. 2003. p 21 7-232. Disponível em <http://unesdoc.unesco.org/images/0013/0013/8//31873por.pdf>. Acesso em abril de 2018.

COELHO, Teixeira. O que é Ação Cultural? São Paulo: Brasiliense, 1989. (Coleção Primeiros Passos; 216 ).

DAVALLON,J.A mediação: a comunicação em processo? Revista virtual Prisma de Ciências da Informação e Comunicação, n. 4. jun. 2007. Disponível em: <http://revistas.ua.pt/index.php/prismacom/article/view/645> .Acesso em: abril de 2018

DE PAULA, Thais Regina Franciscon ; A Mediação em Museus: um estudo do projeto "Veja com as mãos" - 2012 - São Paulo. disponivel em: <https://www. marilia.unesp.br/Home/Pos-Graduacao/Cienciadalnformacao/Dissertacoes/ De_Paula_T_R_F_mestrado_Cl_20I2.pdf> Acesso em outubro de 2017.

DESVALLÉES, André; MAIRESSE, François. Conceitos-chave de Museologia. Tradução: Bruno Brulon Soares, Marília Xavier Cury. ICOM: São Paulo, 2013.

FERREIRA, Aurélio Buarque de Holanda. Mediação. In: FERREIRA, Aurélio Buarque de Holanda. Dicio - Dicionário online de português. 2018. Disponível em < https://www.dicio.com.br/mediacao/ > Acesso em ago. 2018

GROSSMANN, Martin; RAFFAINI, Patrícia T.;TEIXEIRA COELHO. Museu. In: TEIXEIRA COELHO. Dicionário crítico de política cultural. 3. ed. São Paulo: Fapesp/lluminuras, 2004. p. 269-274. Disponível em : <http://hugoribeiro.com.br/ biblioteca-digital/Coelho-Dicionario_critico_de_politica_cultural.pdf $>$ acesso maio de 2018

LOPES, Maria Immacolata V. de. Mediação e recepção. Algumas conexões teóricas e metodológicas nos estudos latino-americanos de comunicação. Matrizes, v. 8, n. I, 2014 .

MANÇANARES, Bárbara Pereira; BORGES, Luiz Carlos. Museologia e Patrimônio, Vol. I0, No 2 (20I7). Disponível em < http://revistamuseologiaepatrimonio.mast. br/index.php/ppgpmus/article/viewArticle/536 > acesso Março de 2018.

MARTINS, Ana Amélia Lage. Mediação e bibliotecas públicas: uma perspectiva dialética. Perspect. ciênc. inf. 2014, vol.19, n.spe, Pp.I64-185. Disponível em <http://www.scielo.br/scielo.php?script=sci_arttext\&pid=SI4I3-993620 I 40005000 I 3\&lng=pt\&tlng=pt> Acesso em I0 de novembro de 2017.

NUNES, Ana Catarina. Filho de peixe sabe nadar: história e estórias com objetos. Midas: Museus e Estudos Interdisciplinares, v. 2016, n. 6, p. I-I, 2016. disponível em: < https://www.ingentaconnect.com/content/doaj/21829543/2016/000 
$02016 / 00000006 /$ art00002 > acesso em abril de 2018 .

OLIVEIRA, Alecsandra Matias de. Epopeia Paulista:A experiência do ateliê-residência no Museu de Arte Contemporânea da Universidade de São Paulo. Midas. Museus e estudos interdisciplinares, n. 4, 20I4. Disponível em: < https://journals. openedition.org/midas/654 > acesso em maio de 2018 . 